\title{
Spor Organizasyonlarında Sosyal Dijital Medya Düzenlemeleri ve Sinsi Pazarlama: 2016 Rio Olimpiyatları Örneği
}

\author{
İbrahim EDİN*
}

\section{Öz}

Dijital transformasyon çağında yeni medya olarak adlandırılan sosyal ve dijital medya uygulamaları sporcu, firma ve tüketiciler/taraftarlar arasındaki etkileşimi farklı bir boyuta taşımıştır. Mobil teknolojilerinde katkısıyla mekan ve zaman engeli tanımaksızın paylaşım yapma imkanı doğmuştur. Spor organizasyonları büyük maliyetlerle düzenlendiğinden sponsorsuz bu organizasyonların üstesinden gelmek mümkün değildir. Bu noktada organizasyonlara ekonomik destek veren sponsor kuruluşlar ile bu desteği vermeksizin farklı gerilla pazarlama yöntemleri ile rekabet avantajı sağlamak isteyen markalar arasında büyük bir mücadele başlamıştır. Pazarlamanın yaratıcılık ile neredeyse eşanlamlı düşünüldüğgu günümüzde sinsi pazarlama (ambush marketing) yöntemleri spor organizasyonlarında sıkılıkla kullanılır olmuştur. Olimpiyat oyunları da bu mücadelenin en büyük savaş alanı olarak görülmektedir. Uluslararası Olimpiyat Komitesi (IOC) de özellikle sosyal ve dijital medya kullanımının etkinliğinin arttığı 2012 Londra olimpiyatları ile birlikte önlemlerini artırmış ve sponsor markaların haklarını koruyan düzenlemeler getirmiştir. 2016 Rio olimpiyatlarında ise daha ileri gidilerek sosyal ve dijital medya düzenlemeleri adı altında olimpiyat sözleşmesinin 40 nolu kuralına dayanılarak yeni düzenlemeler yapılmıştır. Bu düzenlemelere rağmen 2016 Rio olimpiyatlarında yine yaratıcı sinsi pazarlama vakaalarıyla karşılaşılmıştr. Bu çalışma kapsamında spor organizasyonlarında sosyal ve dijital medya uygulamaları, bu yeni medya kanalıyla yapılan pazarlama faaliyetleri ve bu faaliyetler karşısında geliştirilen önlemler ve bu önlemlerin etkinliği incelenmiş ve bu mücadele alanının geleceğine yönelik öngörü ve tespitler yapılmıștır.

Anahtar kelimeler: Rio Olimpiyatları, Sinsi Pazarlama, Sosyal ve Dijital Medya, Kural 40

\section{Ambush Marketing and Social Digital Media Guidelines in Sport Events: Example of 2016 Rio Olympics}

\begin{abstract}
At digital transformation age, social and digital media applications, aka new media, moved the interaction between athletes, brands and consumers/fans into another dimension. Mobile technologies enable people to share their experiences without any time and place limits. Without sponsors it is almost unpossible to organize big sporting events. At that point there is a battle between official sponsors, who are supporting sport events economically and other brands, which aims to have competitive advantage using guerilla tactics
\end{abstract}

* Doç.Dr. Marmara Üniversitesi - Spor Bilimleri Fakültesi, iedin@marmara.edu.tr 
without giving any economic support. Nowadays marketing is almost seen synonyms to innovation, and innovative ambush marketing methods are often used in sport events. Olympic Games has always seen as the biggest battlefield for this tremendous fight. Especially at 2012 London Olympics the diverse use and effiency of social media has increased and IOC has decided to work on some policies to protect the rights of official sponsors asnd trademark of itsself. For 2016 Rio Olympics, these policies linked to social and digital media guidelines, which based on Rule 40 at Olympic Charter. Despite these guidelines, creative ambushers find many ways to promote their brands unofficialy. This paper aims to give brief insight of social and digital media cases in sport events especially at olympics, to discuss the efficiency of policies generated against ambush marketing activities and to forecast the future of these interesting battle between all parties.

Keywords: Rio Olympics, Ambush Marketing, Social and Digital Media, Rule 40

\section{GiRiş}

Birçok kuruluş büyük uluslararası spor organizasyonlarını hedef müşteri gruplarına yönelik pazarlama faaliyetlerini düzenlemek için ideal bir platform olarak görmektedir. Bu noktada olimpiyatlar ve farklı spor dallarında düzenlenen dünya/kıta şampiyonaları markaları cezbeden spor organizasyonları olarak öne çıkmaktadır. Tabi ki bu organizasyonları üstlenen ülke ve şehirler ve organizasyonu düzenleyen federasyon veya komiteler de bu değerli pazarlama kanalının haklarını ciddi rakamlar karşılığında pazarlamaktadır.

Teknolojinin hızlı gelişimi ve sosyal medya kullanımının yaygınlaşması sonucunda spor pazarlaması ve spor organizasyonlarında yer alan resmi sponsorların haklarının korunması arasındaki mücadelede özellikle 2012 Londra Olimpiyatlarıyla birlikte farklı bir döneme girilmiştir. Son yıllarda sosyal medya kullanıcıları spor organizasyonlarında resmi yayıncıların ve akreditasyon almış basın mensuplarının görevini üstlenerek eşzamanlı olarak müsabakalardan yayın ve haber paylaşımında bulunmaktadır.

Günümüzde birçok sosyal medya platformu hem sporcuların hem de katılımcıların, taraftarları ve spora ilgi duyan takipçileriyle görüntü, mesaj ve resim paylaşımına imkan tanımaktadır. Bu noktada en büyük problem spor organizasyonunun yayını için milyarlarca dolar ödeyen yayıncı kuruluşlar ve organizasyonda reklam veren ve organizasyonun yapılmasını sağlayan sponsorların haklarının korunması ve buna yönelik tehditlerin yapılacak düzenlemelerle kontrol altına alınması olarak görülmektedir.

2012 Londra Olimpiyatları́nda sponsor markaların korunmasına yönelik oldukça başarılı olunmakla birlikte, teknoloji ve yaratıcılık faktörleri gözetildiğinde her organizasyonda farklı yöntemler ortaya çıkmakta ve bunlara karşı alınacak önlemler de çeşitlenmektedir. Bu noktada sinsi pazarlama taktikleri sınır tanımamakta ve kuruluşlar yasal boşluklardan da yararlanarak daha az maliyetle bazen milyarlarca kişinin izlediği spor organizasyonlarında markalarının tanıtımını yapma imkanı bulmaktadır. 
2016 Rio Olimpiyatlarında daha önceki oyunlarda elde edilen deneyimler doğrultusunda hem Uluslararası Olimpiyat Komitesi (IOC) hem de Brezilya hükümeti ve Rio Belediyesi geliştirilmiş önlemleri devreye sokmuştur.

Bu çalışma kapsamında özellikle sosyal medya uygulamaları ön planda tutularak mega spor organizasyonlarındaki pazarlama ve sosyal medya problematiğinin derinlemesine incelenmesi, örneklerle problemlerin boyutunun ortaya koyulması, alınan hukuki ve etik önlemlerin irdelenmesi ve bu sorunun geleceğine yönelik bazı çıkarımlar yapılması hedeflenmiştir.

\section{Sporda Sinsi Pazarlama}

Sporda sinsi pazarlama, ilgili spor organizasyonunda pazarlama haklarına sahip olmadan, pazarlama faaliyetlerini farklı biçimlerde şekillendirerek bu organizasyonla bağlantısı varmış gibi göstererek rekabet avantajı sağlamak olarak tanımlanmaktadır (Nufer, 2016). Sinsi pazarlama konusunda yazında farklı tanımlarla karşılaşılmaktadır, buradaki tanım farklılıkları genelde sinsi pazarlamanın uygulamadaki destekleyicileri ve karşıtları arasında görülmektedir (Ellis ve ark., 2011). Sinsi pazarlama ilk olarak Bayless tarafindan 1988'de bir etkinlikte resmi sponsorlara karşı avantaj sağlamak için popüler bir taktik olarak tanımlanmıştır. Meenaghan (1994) ise sinsi pazarlamayı, firmaların çoğunlukla da rakip olan resmi sponsorlardan ilgiyi uzaklaştırarak kendilerine yöneltmesi faaliyeti olarak tanımlamaktadır. Daha yakın bir tarihte ise bu kavram pseudo-sponsorluk olarak adlandırılmış ve ilişkisel pazarlamanın bir formu olarak görülmüş ve bir işletmenin etkinlikle resmi ve direk bağlantısı olmadan bağlantısı varmış gibi göstererek ilgi, farkındalık ve benzer faydaların sağlanması olarak tanımlanmıştır (Chadwick, Burton, 2011).

Bu pazarlama çeşidi karşıtlar tarafından, yüksek fiyatlarla elde edilmiş sponsorluk haklarının çalınması olarak tanımlanmakta ve bunu yapan işletmeler hırsız olarak adlandırılmakta ve sinsi pazarlamanın yasal ve etik olmayan hususları vurgulanmaktadır (Welsh, 2002 ve Payne, 1998). Taraftarlar ise, sinsi pazarlamanın her zaman yasal olmayan pazarlama aktiviteleri olarak karşımıza çıkmadığını, işletmelerin paydaşlarına yükümlülükleri doğrultusunda etkin ve maliyet odaklı yaratıcı pazarlama faaliyetleri olduğunu öne sürmektedir (Grady, 2010).

Sonuçta sinsi pazarlama gerilla pazarlamanın bir çeşidi olarak, yaratıcı fikirlerle yasal alana saygılı ve etik kuralları çiğnemeden yapılan bir faaliyet olarak görülmelidir. Pazarlamanın özü yaratıcılık doğrultusunda yaygın biçimde kullanılmaktadır. Özellikle teknolojik gelişimler pazarlamacıların bu alanda etkinliklerini artırmış ve günümüzde oldukça fazla karşılaşılan bir olgu olarak görülmektedir.

Micheal Payne IOC üyesi, 1998 yılında yayınlanan makalesinde sinsi pazarlamanın olimpiyat oyunlarının geleceğine oluşturduğu tehditi dile getirmiş, bu pazarlama şeklinin hak edilmemiş bir avantaj sağladığını ve ticari sponsorların olimpiyatlara olan katkısının olumsuz etkileneceğini ifade etmiştir (Payne, 1998). 
Olimpiyatlarda yeni medya olarak adlandırılan sosyal ve dijital medyanın sinsi pazarlama alanında kullanımına yönelik yapılan bir çalışmada, büyük spor organizasyonlarında spor tüketicilerinin ve sporcuların izleyicileriyle mobil teknolojilerin de yardımıyla her geçen gün daha fazla sosyal medya üzerinden etkileşimde bulunduğu ifade edilmiş ve bu alanda olimpik sponsorluğun korunmasına yönelik tespitlerde bulunulmuştur (Grady, 2011).

2011-2014 yılları arasında Amerika'da Catalyst/IMG tarafindan yapılan taraftar katılım araştırmalarında dijital ve sosyal medyanın spor alanında etkilerinin artışı takip edilmiş ve kayda değer saptamalar yapılmıştır. Bu araştırmalarda, spor takip ve tartışma amacıyla sosyal medya kanallarının kullanımında Facebook, Youtube, Twitter, Google+ ve Instagram öne çıkmıştır. Maç günlerinde sosyal medya kullanımı Twitter ve Facebook'ta 5-6 katına kadar çıkmaktadır. En son 2014 yılında yapılan araştırmada Vimeo, Pinterest de artan kullanımlarıyla dikkat çekmiştir. Sosyal medya spor haberleri ve bilgi kaynakları arasında televizyon ve web sayfalarının ardından üçüncü sıradaki yerini korumaktadır. Geleneksel haber kaynakları olan gazete, radyo ve dergilerin önünde yer almaktadır. Ancak yine bu araştırmaya göre güvenilirlik konusunda sadece dergi haber kaynağının önünde beşinci sırada yer bulabilmektedir. Paylaşılan içeriklerde ise maç özetleri ve skorları/istatistikleri, maç sonrası röportajlar, oyuncu istatistikleri, maç öncesi görüşler, oyuncu sakatlık haberleri sırasıyla yer almaktadır (Catalyst/IMG, 2014).

Olimpiyatlarda sinsi pazarlama uygulamalarının geçmişine baktığımızda 1996 Atlanta Olimpiyatları’nda Nike firmasının olimpiyat köyünün hemen yanında 'Nike Köyü’nü' konumlandırmasıyla birçok katılımcı Nike’ın resmi sponsor olduğunu düşünmüştür, ancak gerçek bundan farklıdır. 1994 kış oyunlarında ise AMEX, oyunların resmi sponsoru olan VISA'ya karşı bir reklam kampanyası düzenlemiş ve 'Norveç'e seyahat ediyorsanız, pasaporta ihtiyacınız var, VISA kartına değil' sloganıyla tüketicileri hangi firmanın resmi sponsor olduğu konusunda şüpheye düşürmeyi başarmıştır. 1996 olimpiyat oyunlarında atlet Linford Christie taktığ1 lenslerle dikkati çekmiş ve oyunların resmi sponsor Reebook olmasına rağmen kullandığı Puma logolu lenslerle basın toplantısına girerek medyada büyük bir ilgi uyandırmıştır. 2012 Londra Olimpiyatlarında organizasyon komitesi yüzlerce polis eşliğinde izinsiz olimpiyat markasını kullanan yerel işletmelere ceza yağdırmış, sebep olarak da olimpiyat markasının kullanım haklarının ihlal edilmesini göstermişlerdir.

İşin ilginç tarafı bir organizasyonda sinsi pazarlama fikrinin sahibi olarak markalar, bir başka organizasyonda rakip firmanın sinsi pazarlama taktikleriyle karşı karşıya kalabilmektedir.

\section{Sporda Sosyal Medya Kullanımının Rolü}

Sosyal medya, Web 2.0 teknolojisi kullanılarak kullanıcı kaynaklı içeriklerin oluşturulması ve paylaşımını sağlayan internet tabanlı uygulamalar olarak tanımlanmaktadır (Kaplan ve Haenlin, 2010). Sosyal medya taraftarların ilgisinin çekilmesi ve yapılan spor organizasyonuna olan farkındalığının artırılması için yeni ve tam olarak anlaşılamayan iletişim ve etkileşim metodu olarak tanımlanmış ve 'Yeni Medya' olarak adlandırılmıştır (Pickton ve Broderick, 2005). Kaplan 
ve Haenlin sosyal medyayı altı kategoride sınıflandırmıştır; işbirlikçi projeler (Wikipedia), blog ve içerik toplulukları (Youtube), sosyal ağ iletişim siteleri (Facebook), sanal sosyal dünyalar (Second Life), sanal oyun dünyaları (World of Warcraft). Spor endüstrisi içinde sosyal medyanın, pazarlama iletişim aracı olarak kullanımına yönelik akademik çalışmaların sayısı da hızla artmaktadır. Bu alanda özellikle tüketici geri dönüşümleri (Mahan, 2011), tüketicilerin sosyal medya kullanımı (Clavio, 2011), spor organizasyonlarında taraftarların dahil edilmesi (Iokimidis, 2010), spor organizasyonları sosyal medya web sitesi içerikleri (Waters ve ark. 2010), sporcuların sosyal medya üzerinden tanıtımları (Butts, 2008) konularında çalışmalar yapılmıştır.

Özellikle spor organizasyonları konusunda Iokimidis'in çalışmasında, çevrimiçi toplulukların oluşturulması tüketici ve taraftarların sanal ortamda diğer katılımcılarla bağlantı sağlamasını, düşüncelerini paylaşmasını ve bir nevi organizasyona bağlılık duygusunu artıracağını ifade etmektedir. Yine Broughton'un araştırmasına göre (2010), taraftarlar takımlarını Facebook ve Twitter üzerinden takip etmeye başladıktan sonra kendilerini 'büyük taraftar' olarak değerlendirmişlerdir.

Sporda sosyal medya kullanımının ve etkisinin artışını dijital dönüşüm sürecinden bağımsız düşünmemek gerekmektedir. Dijital dönüşüm sporda da ciddi etkiler yaratmakta ve enformasyon ve bilgiye ulaşımın kolaylaşması sonucunda farklı iletişim teknolojilerinin kullanımı da gündeme gelmektedir. Klasik haberleşme ve iletişim yöntemlerinin yetersiz kaldığı günümüzde bireyler haber paylaşımını sosyal ağlar üzerinden gerçekleştirmekte ve mobil teknolojinin de katkısıyla zaman ve mekandan bağımsız paylaşımlar yapabilmektedirler.

Sporda sosyal medyanın iletişim ve reklam amaçlı kullanımı her geçen yıl artmaktadır. Özellikle taraftarların sporcularla etkileşiminde sosyal medya platformları büyük ölçüde kullanım bulmaktadır. Youtube video paylaşımı alanında sınırsız bir kullanım sağlamakta, Twitter haber paylaşımında geleneksel medya kanallarının önüne geçmekte ve Facebook taraftarlarla etkileşimde büyük imkanlar sağlamaktadır.

NBA takımları üzerinde yapılan bir çalışmada sosyal medya kullanımı ve stratejileri konusunda ciddi girişimler yapıldığı, sosyal medya uzmanlarının istihdam edildiği ve özellikle sosyal medyanın pazarlama aracı olarak kullanımına yönelik çalışmaların önem kazandığ belirtilmektedir (Wysocki, 2012). Bu çalışmada spor iletişimi ve taraftar ve diğer paydaşlarla etkileşim aracı olarak sosyal medya kullanımının önemi vurgulanmıştır.

Bir başka çalışmada sosyal medya taraftar sayfaları üzerinden pazarlama faaliyetleri incelenmiştir. Sponsor firmaların sosyal medya kanalıyla ileti ve haber paylaşımları değerlendirilmiş, bu paylaşımların sporcu ve takım taraftarları tarafından olumlu algılandığı ve markaya katkı verdiği görülmüştür. Ayrıca ilgili taraftarların sosyal medya üzerinden paylaşımları ile pazarlama etkisinin artırıldı̆̆ı ve bu nedenle markaların iletişiminde sosyal medyanın giderek önem kazandığı belirtilmiştir (Bartoletti, 2013). 
Sosyal medya, spor organizasyonları ve bu organizasyonlara katılanlar açısından düşük maliyetli bir pazarlama ve iletişim aracı olarak görülmelidir, bu da hem kullanımı hem de etki oranını artırmaktadır. Ancak yapılan çalışmalarda sosyal medyanın hala iletişim aracı olarak kullanımının pazarlama hedeflerinin üstünde yer aldığı da görülmektedir (Eagleman, 2013).

Olimpiyatlarda sosyal medya ile ilgili Twitter kullanımı üzerine yapılan çalışmalardan birinde 2012 Londra olimpiyatları incelenmiş, sosyal medya paylaşımlarının düzenlenmesi ve sponsorların sinsi pazarlama karşısında korunmasına yönelik tedbirler değerlendirilmiştir (Grady, Ballouli, Pressley ve Moorman, 2013).

\section{Olimpik Antlaşma-Kural 40 ve Rio Olimpiyatlarında Pazarlama ve Sosyal Medya İlkeleri}

Uluslararası Olimpiyat Komitesi (IOC) tarafından ilk kez 1908 yllında yayınlanan Olimpik Antlaşma günümüzdeki haliyle son olarak Ağustos 2015’te revize edilmiştir. Olimpik antlaşma olimpiyat oyunlarının organizasyonu için belirlenen kural ve ilkeleri belirleyen ve olimpik hareketin yönetimini sağlayan yazılı bir belgedir. Olimpik antlaşma temelde üç amaca hizmet etmektedir; olimpizm prensiplerinin ve değerlerinin tesis edilmesi ve korunması, IOC yasası olarak referans sağlaması, olimpik hareketin temel aktörlerinin (uluslararası olimpiyat komitesi, uluslararası federasyonlar, ulusal olimpiyat komiteleri ve olimpiyat oyunları düzenleme komiteleri) hak ve yükümlülüklerinin belirlenmesi. Altı bölüm ve 61 kuraldan oluşan olimpik antlaşmada 7 temel olimpizm prensibi, olimpik hareket ve uygulaması, uluslararası olimpiyat komitesi, uluslararası federasyonlar, ulusal olimpiyat komitesi, olimpik oyunlar ve önlemler, yaptırımlar, disiplin prosedürleri ve ihtilafların çözülmesi bölümleri yer almaktadır.

IOC sosyal ve dijital medya ilkelerinin dayandığı Kural 40, olimpiyat oyunlarına katılım başlı̆̆ı altında olimpiyat oyunlarına katılacak olan sporcu, antrenör, yönetici ya da sair takım görevlilerinin, olimpiyat oyunları süresince kendisinin, adının, fotoğrafının veya spordaki performansının reklam amaçları doğrultusunda kullanılmasına izin vermemesi gerektiğini düzenlemektedir.

Olimpik antlaşmada yine Kural 49 ve 50, olimpiyat oyunlarına ilişkin yayınları ve reklam, gösteri ve propaganda faaliyetlerini düzenlemektedir. Buna göre Kural 49’da olimpiyat organizasyon komitesi ilgili basılı materyalin IOC standartlarında üretiminden ve dağıtımından sorumludur. IOC tarafından onaylanmayan hiçbir belge ve yayın, olimpiyat oyunlarında kullanılamaz. Kural 50 ise reklam ve PR faaliyetlerinin düzenlenmesine yönelik oluşturulmuştur. IOC buna yönelik prensip ve ilkeleri belirlemiş ve olimpik alanların bir parçası olarak adledilen stadyum, tesis ve diğer yarışma alanlarının reklam ve diğer PR unsurlarının uygulamasına yönelik düzenlemeleri sınırlamıştır.

Ekim 2015’te IOC yayınladığı sosyal ve dijital medya ilkelerinde, Rioda düzenlenen 31. Olimpiyat Oyunlarına akredite olmuş kişilerin uyması gereken kuralları belirlemiştir. Kural 40 altında izne bağlanan paylaşım ilkelerinin netleştirildiği bu belge yıllardır süregelen bir karmaşaya da düzen getirmek yolunda önemli bir adım olmuştur. 
Bu düzenlemeye göre IOC olimpiyat katılımcıları ve akredite olmuş kişilerin izlenim ve olimpiyat tecrübelerini arkadaş, aile ve taraftarlarıyla sosyal ve dijital medya üzerinden paylaşımını teşvik ettiğini belirtmekle beraber bunun belli kurallar doğrultusunda yapılmasına izin vermiştir. Bu düzenlemede süre, olimpiyat köyünün açılışından olimpiyat oyunlarının kapanışına kadar belirlenmiş, bu süre zarfında akredite kişiler hariç kişilerin muhabir ve haberci gibi davranarak haber veya yayın yapması yasaklanmış, olimpiyat oyunlarındaki tecrübelerin paylaşımı katılımcılar tarafından günlük formatında ve belirlenen ilkeler doğrultusunda sosyal ve dijital medya kanalıyla yapılması kabul edilmiştir. Bu paylaşımlarda ırkçı, politik ve dinsel söylemlerden uzak durulması özellikle vurgulanmıştır. $\mathrm{Bu}$ düzenlemeler olimpik değerlerin ve üçüncü partilerin haklarının korunmasına özen göstermektedir. Burada üçüncü partiler uluslararası ve milli olimpiyat komitesinin anlaşma yaptığı yayın kuruluşları ve sponsorlar olarak görülmektedir. Sonuç olarak bu düzenleme olimpiyatlar boyunca katılımcı olarak bahsedilen sporcu, antrenör, medya mensubu, yönetici ve organizasyon çalışanlarının sosyal medya üzerinden yapacakları paylaşımlarda olimpik değerlerle birlikte olimpiyatın maddi kaynaklarını sağladığı ortaklarının çıkarlarına zarar vermemesi üzerine kurgulanmıştır.

Bu düzenlemede özellikle vurgulanan metin ve resim paylaşılan sosyal medya mecralarından Facebook, Instagram, weibo, Vkontakte ile live-streaming (canlı yayın) özelliği bulunan periscope ve meerkat uygulamalarıdır. Ayrıca profesyonel fotoğraf çekimi ekipmanı olarak belirtilen tripod ve profesyonel TV ekipmanlarının kullanımı sınırlandırılmıştır.

$\mathrm{Bu}$ düzenlemede ayrıca sosyal medya üzerinden yapılan paylaşımlarda olimpik marka ve mülkiyet olarak görülen bazı etiketlerin (hashtag) kullanımına sınırlama getirilmiştir. Olimpik IP üzerinden olmadıkça katılımcılar tarafından kullanımına yasak getirilen etiketler; 2016, olimpiyat, Rio/Rio de Janerio, oyunlar, altın, gümüş ve bronz, madalya, performans, yarışma, yaz, sponsorlar, zafer olarak belirlenmiştir (Emig, 2016).

Olimpik sözleşme Kural 59'da ise sosyal medya ve pazarlama ilkelerine aykırı davranan katılımcılara uygulanacak yaptırımlar belirlenmiştir. Buna göre, herbir olay bağımsız değerlendirilerek soruşturulacak, akreditasyon kaybı dışında elde edilen madalyaların iadesi ve sporcuların müsabakalardan diskalifiye edilmesine kadar yaptırımlar uygulanabilecektir.

Olimpik sözleşmedeki yaptırımlar dışında yerel kanunlar da bu ilkelere aykırı davranan katılımcılar hakkında cezai yaptırımlar öngörmektedir. Brezilya hükümeti tarafından çıkartılan yasalarda olimpik sembollerin izinsiz kullanımı, olimpiyatla ilgili ürünlerin ticari satışı ve sinsi pazarlama girişimlerine karşı cezai yaptırımlar belirlenmiştir. Buna göre 10.05.2016 tarih ve 13284 sayılı kanun; olimpik sembollerin izinsiz kullanımı için 3 aydan 1 yıla kadar hapis cezası veya para cezası; olimpiyatla ilgili ürünlerin ticareti durumunda 1 ila 3 ay hapis cezası veya para cezası; sinsi pazarlama girişimleri ise 3 aydan 1 yıla kadar hapis veya para cezası öngörülmektedir. Ayrıca yine ilgili kanun maddesi uyarınca bu girişimlerde bulunanlar sebebiyet verdikleri zararı ve elde ettikleri haksız kazancı tazmin etme durumundadırlar. 


\section{I6 Rio Olimpiyatlarında Sosyal Medya Kanalıyla Sinsi Pazarlama Girişimleri}

Sosyal ve dijital medyanın artan kullanımı ile olimpiyat oyunlarında da sinsi pazarlama girişimleri ciddi boyutlara ulaşmıştır. Özellikle 2012 Londra Olimpiyatları ile birlikte bu alanda resmi sponsorların korunması amacıyla ciddi bir mücadele başlamıştır. Buna yönelik Rio Olimpiyatları̉nı kapsayacak biçimde yapılan düzenlemeler genel anlamda başarıya ulaşmıştır, ancak yine de düzenlemelerin koyduğu sınırlar dahilinde başarılı olan kampanyalar da olmuştur. İlgili vakalar bu çalışma kapsamında değerlendirilerek sinsi pazarlama ve sponsorluk arasındaki mücadeleye farklı bir boyut getirilmesi hedeflenmektedir.

Öncelikle 2016 Rio olimpiyatlarının sponsorluk yapısına kısaca bakarsak, sponsorların ulusal ve küresel boyutta iki gruba ayrıldığını görmekteyiz. Olimpik küresel ortaklar altında Coca Cola, Atos, Bridgestone, Dow, General Electric, Mc Donalds, Omega, Panasonic, P\&G, Samsung ve Visa yer almaktadır. Bu gruba 2017 yılından itibaren Toyota da katılacaktır. Adweek.com’un çalışmasına göre 5 Ağustos ve 22 Ağustos tarihleri arasında yaklaşık 217 bin olimpik mesaj paylaşılmış ve Coca Cola, Samsung ve Visa ilk üç sırada yer almıştır. Yerel organizasyon komitesi sponsorları arasında ise Claro, Bradesco, Nissan, Embratel ve NET öne çımaktadır. Olimpiyat gelir kaynakları arasında iki önemli kalem dikkati çekmektedir, bunlardan ilki olimpiyat oyunlarının yayın hakları, diğeri ise sponsorluklardır. 1984 Los Angeles olimpiyatlarından beri önemli spor etkinlikleri yayın haklarından elde edilen gelirlere daha fazla bağımlı hale gelmiştir. Bu noktada 2016 Rio Olimpiyatlarına bakıldığında IOC toplam gelirleri 5,6 milyar dolar olarak tahmin etmekte ve bu gelirlerin \%74'ü yayın haklarından elde edilmektedir. Örneğin Amerikan NBC yayın kuruluşu ABD bölgesindeki yayınlar için 2020 yılına kadar 4,4 milyar dolar ödeme yapmıştır. Yayın hakları ülke veya bölge olarak verilmekte ve genelde konsorsiyum olarak yayın ihaleleri alınmaktadır. Burada da konsorsiyum üyeleri 120-160 milyon dolar ödeme yapmaktadır. Yayın haklarından 2013-2016 yılları arasında elde edilecek gelir IOC tarafından 4,1 milyar dolar olarak öngörülmüştür (IOC Marketing: Media Guide, 2016).

Sponsorluklar ise IOC global sponsorları ve yerel organizasyon sponsorları olarak ayrılmaktadır. IOC global sponsorlardan yaklaşık 2 milyar dolar gelir elde etmektedir, bu gelirler yerel organizasyon komitesi için 1 milyar dolar civarında gerçekleşmiştir. Hal böyleyken resmi sponsor olmayan bazı markalar yine yaratıcı pazarlama kampanyaları ile rekabete farklı bir boyut katmışlardır.

\section{Apple Saat Kayışları}

Apple önde gelen 14 ülkenin bayrak renklerini içeren ve bir nevi olimpik his veren saat kayışlarını olimpiyatlar süresince Apple mağazalarında satarak, IOC’ye herhangi bir sponsorluk bedeli ödemeden ticari bir faaliyet göstermiştir. Olimpiyatların resmi telefon sponsoru olan en büyük rakibi Samsung karşısında bu faaliyet akıllı bir gerilla pazarlama faaliyeti olarak değerlendirilmiştir. Birçok olimpik sporcu bu kayışların bulunduğu Apple saatleri olimpiyatlar boyunca kullanmıştır. Amerikalı atlet Bromell sosyal ve dijital medya düzenlemelerinde belirtilen 
yasak periyodundan 6 gün önce de Twitter hesabından paylaşımda bulunmuştur. Bu konuda Rio organizasyon komitesi yetkilisinin yaptığı açıklamada, olimpik logo kullanılmadığından bu ticari faaliyetin kurallar dahilinde değerlendirildiğini belirtmiştir.

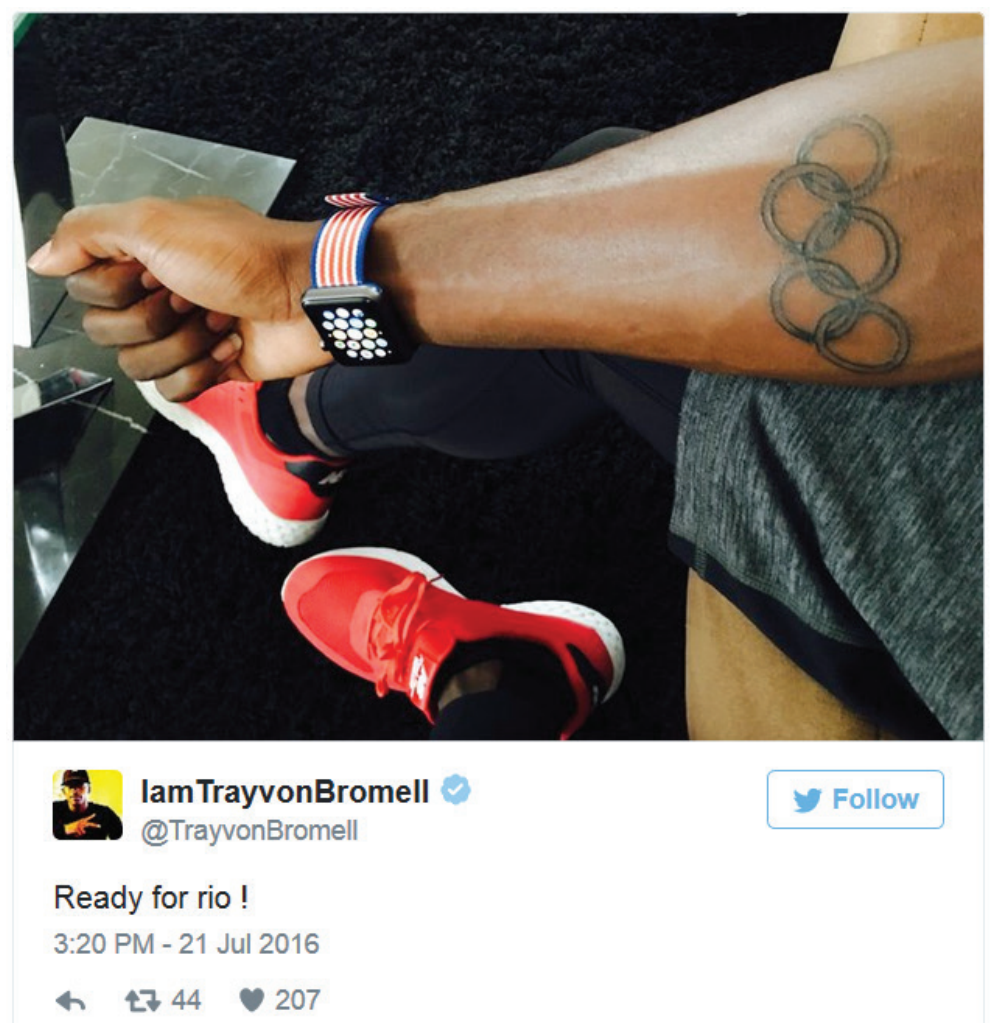

Resim I. Apple Saat Kayışları

Kaynak: Twitter, @TrayvonBromell

\section{Beats Kulaklık}

Micheal Phelps, 22 olimpik madalyası bulunan efsanevi yüzücü Rio olimpiyatlarında 4x100 serbest takım yarışından önce kulaklığın yan tarafındaki marka logosu fark edilince marka logosunun flaster ile kamufle edilmesi yönünde zorlanmıştır. Ancak yüzücüye bu şekilde müsabakaya katılım izni verilmiştir, fakat bir süre sonra kameralara yansıyan sahnede Phelps'in kulaklığının üst kısmında markanın tam adı görünmüştür, bu şekilde flaster sansürünün sinsi pazarlama stratejisi karşısında yetersiz kaldığ 1 bir durum ortaya çıkmıştır. Bu konuda gerçekleşen yaptırımlara karşın birçok sporcu ilgili markanın kulaklıklarını olimpiyatlar süresince kullanmıştır (Gaines,2016). 


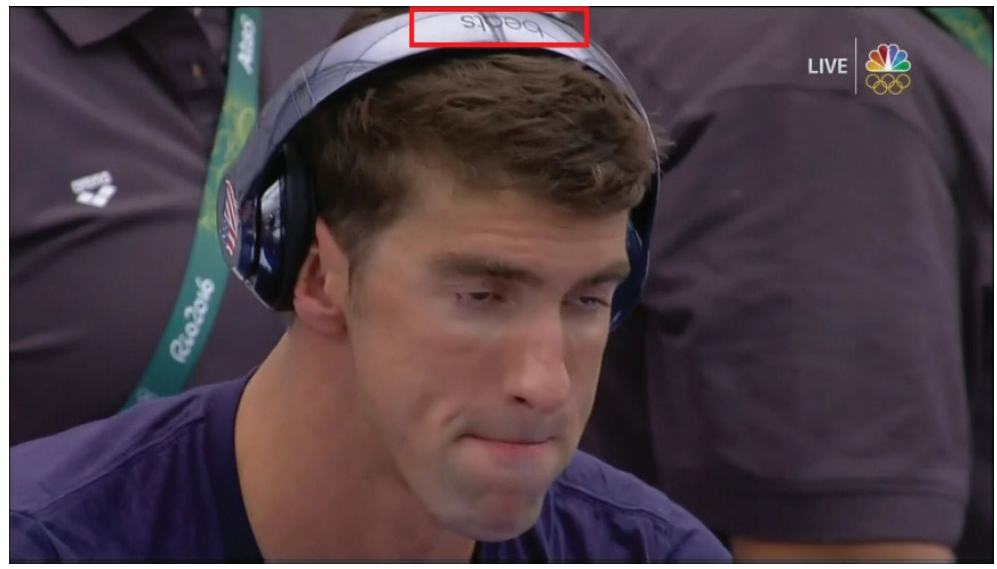

Resim 2. Beats Kulaklık-Micheal Phelps

Kaynak: NBC

\section{Oiselle Kadın Spor Giyim}

Oiselle olimpiyatlar süresince Kural 40 karşıtı kampanyalarıyla dikkat çekmiştir. Olimpik kelimelerin sansürlenmesine karşı oldukça yaratıcı kampanyalar düzenleyerek tüketici üzerinde kalıcı bir etki yaratmıştır. Kullandıkları yaratıcı etiketler arasında \#freebird16, \#TheBigEvent öne çıkmaktadır (arcelea.com, 2016).

welcomed my girlfriend Kate Grace to the team by making her support system of 5 years, Oiselle, delete all images of her winning the USA Trials and realizing her ___ Dream.

This company, these people, have stuck with her through all the highs and lows that come with chasing the Dream. They have not only supported her financially, but have been part of her emotional bed rock for all these years and they are there for her now as she prepares to try ... See More

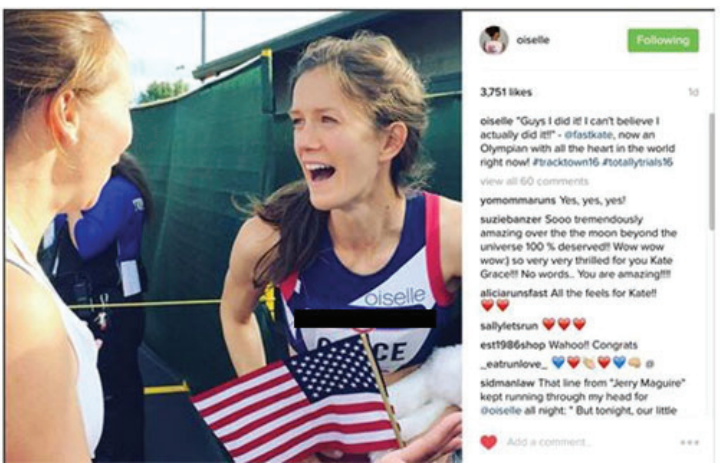

Resim 3. Oiselle Blog 


\section{Under Armour-Rule Yourself Kampanyası:}

Bu olimpiyatların belki de en çok konuşulan ve yaratıcı kampanyası Under Armour markasının ABD olimpiyat takımı sporcularıyla yaptığı kampanya olmuştur. Bu kampanyayla ABD olimpiyat komitesi $\mathrm{ABD}$ olimpiyat takımı resmi sponsoru Nike karşısında ciddi bir pazarlama başarısı sağlanmıştır. Bu kampanyada başta Micheal Phelps olmak üzere ABD cimnastik takımı yer almıştır ve herhangi bir olimpiyat vurgusu olmadan yapılan bu reklam kampanyası Youtube üzerinden 10 milyon görüntülemeye ulaşmış ve en fazla paylaşılan ikinci olimpiyat reklamı olmuştur. Kuralını kendin koy (rule yourself) vurgusu da Kural 40 karşıtı güzel bir algı yaratmıştır.

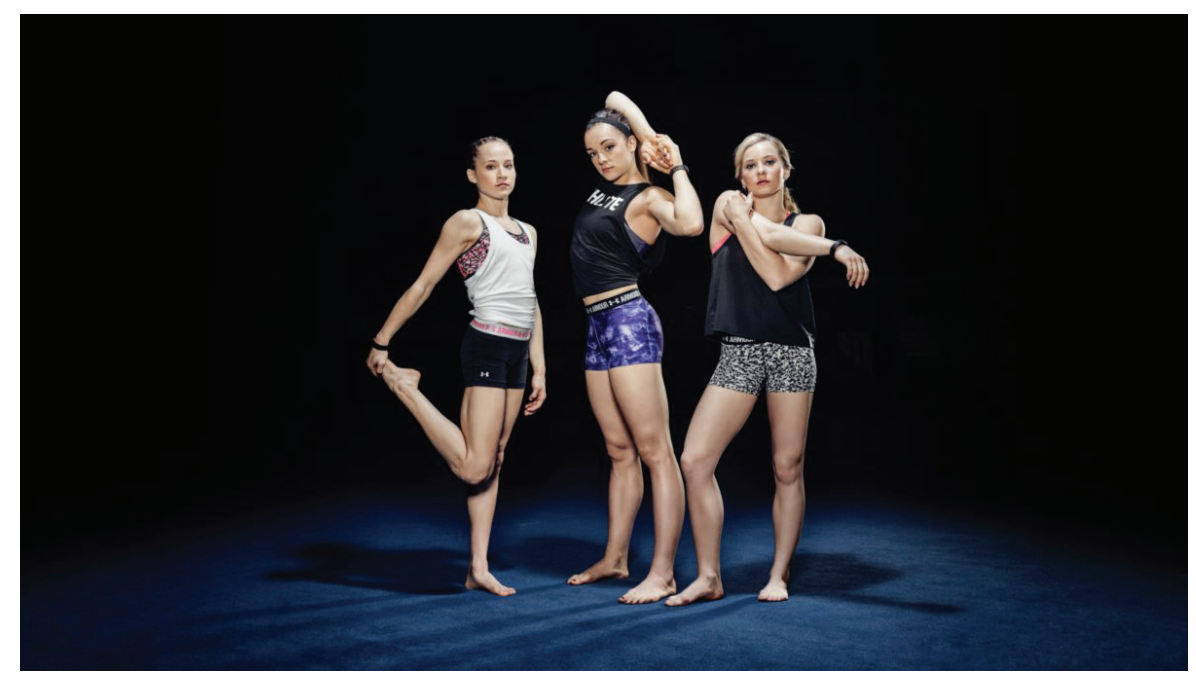

Resim 4. Under Armour-Rule Yourself kampanyası

Kaynak: https://www.underarmour.com/en-us/usa-gymnastics, 05.08.2016.

\section{Brooks Running Co.}

Kanada kökenli Brooks spor giyim markası olimpiyat komitesinin getirdiği kısıtlamaları protesto amaciyla Instagram ve Twitter üzerinden sponsoru olduğu olimpik sporculara mesaj göndererek resmi sponsor olmayan markaların kısıtlanmasına yönelik tepkisini göstermiştir. Sponsoru olduğu sporculara yasaklar başlamadan 'başarı dilemiş ve siz kendinizin kim olduğunu biliyorsunuz ve bu başarıları elde etmek için nerede hazırlandığınızı da' mesajını vererek aslında başarılarının arkasında asıl sponsorlarının markaları olduğunu ima etmiştir. Ayrıca Brooks, bağlantılı olduğu sonradan Wall Street Journal tarafından ortaya çıkarılan Rule40.com sitesi üzerinden düz renk t-shirt üzeri sadece sarı bir etiket ve üzerinde farklı mesajlar olan ürünleri satışa sunmuştur. Bu mesajlar 'koşu t-shirt'ü' ve 'kural 40'a uygun spor giyim' gibi olimpiyat komitesinin düzenlemelerini eleştiren içeriklere sahiptir (Krashinsky, 2016). 


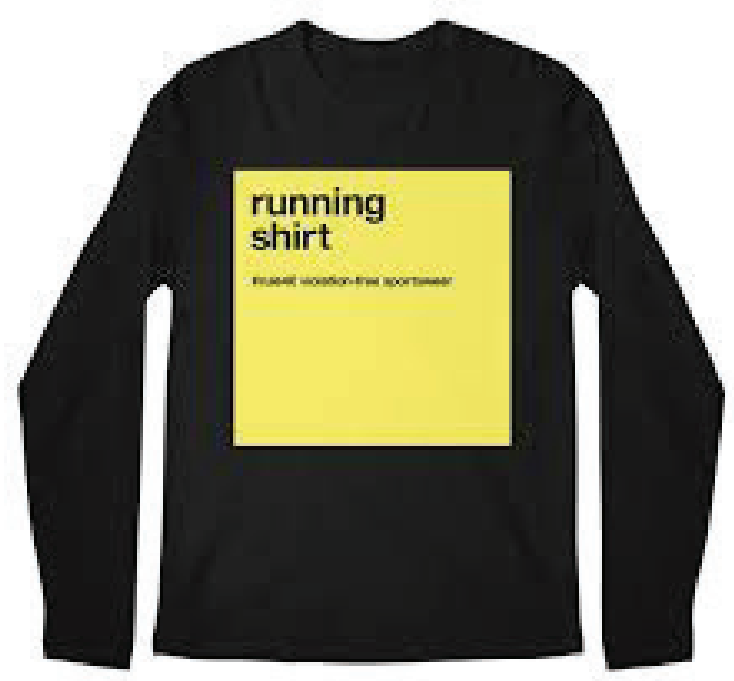

Resim 5. Brooks-Rule40.com t-shirt

\section{Uber}

Mobil uygulama üzerinden hizmet veren ulaşım firması Uber Rio olimpiyatlarında akıllıca bir pazarlama politikasıyla resmi sponsor Visa ile ortaklaşa Visa kullanımlarında bedava seyahat kampanyası düzenlemiştir. Ayrıca Rio havaalanında Uber durakları kurarak olimpiyatları izlemeye gelen potansiyel tüketicilere etkin bir tanıtım sağlamıştır, ABD konsolosluğu tarafından tavsiye edilen ulaşım yöntemi olarak vurgulanmış ve Riónun güvenlik sorunlarından fayda sağlamıştır. Bu şekilde aslında Rio olimpiyatlarının gayriresmi ulaşım markası olarak oyunlara damgasını vurmuştur (Portela, 2016).

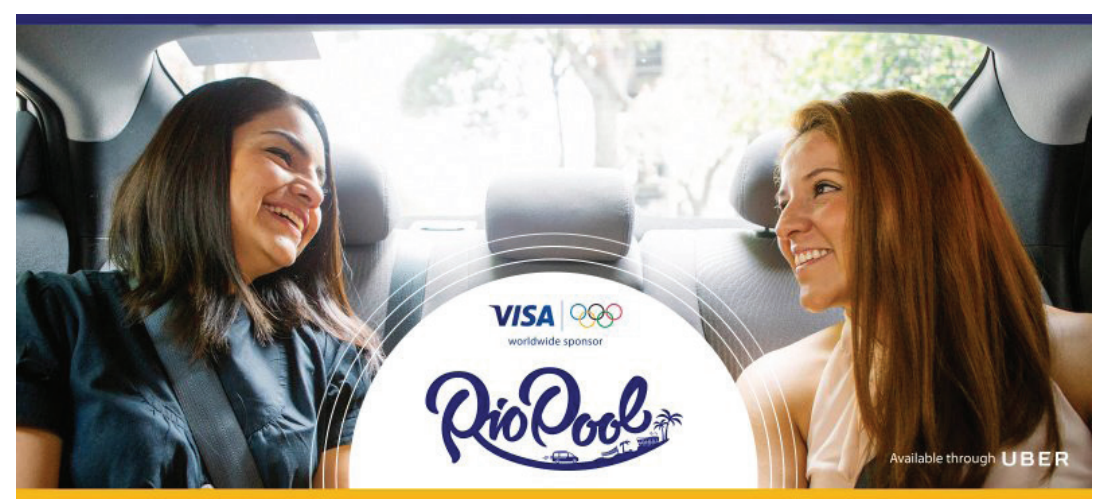

Resim 6. Uber-VISA, RioPool-bedava yolculuk kampanyası 
$\mathrm{Bu}$ örnekler dışında da Puma, Nike, Nintendo, Ford gibi firmaların da başarılı kampanyaları dikkati çekmiştir. Nike, 'Unlimited You' (Sınırsız Sen) kampanyasıyla Facebook ve Youtube hesapları üzerinden 41 milyon izleyiciye ulaşmış ve sadece ABD olimpiyat komitesi sponsoru olarak Rio olimpiyatlarında ciddi bir paylaşım ve tüketiciye ulaşım sağlamıştır. Puma, sürekli sinsi pazarlama yapan bir firma olarak, gene Usain Bolt üzerinden kampanyalarını şekillendirmiştir. Ford ise 'life is a sport' (hayat spordur) kampanyası ile sosyal medyada son yıllarda popülerliği hızla artan Snapchat üzerinden olimpik temalar kullanılmadan uygun zamanda araba ile birlikte farklı sporları birleştirerek başarılı bir çalışma yapmıştır.

\section{SONUÇ VE ÖNERILER}

Olimpiyatlar ve diğer büyük spor organizasyonları gerilla ve dolayısıyla önemli bir parçası olan sinsi pazarlama faaliyetlerinin mücadele alanı olacaktır. Getirilen kurallar bir şekilde düzen sağladıysa da yaratıcı pazarlamacılar yine de değişik fikirlerle olimpiyatlara damgasını vurmuştur.

Kural 40 ve 2016 Rio olimpiyatlarında uygulanan sosyal ve dijital medya ilkeleri insan hakları açısından ciddi biçimde sorgulanmaktadır. Örneğin sponsorunuz ilgili organizasyonun resmi sponsoru ise sosyal medya aracılığıyla yapacağınız tüm pazarlama ve tanıtım faaliyetleri yasal olmakta, ancak sponsorunuz resmi sponsor listesinde değilse kısıtlamalarla karşı karşıya kalınmaktadır. Bu durumda sporda eşitlik ve adalet konularında ciddi bir tartışma oluşmaktadır.

Pazarlama yenilik demektir, bu noktada enformasyon ve iletişim teknolojileri her zaman pazarlama uzmanlarının yeni pazarlama yöntemleri geliştirmesinde yardımcı olacaktır.

Bir diğer sorunsal olan sponsorluk müessesesinde otoriteler 'ekonomik' sponsorluk modelleri geliştirerek sponsorların daha geniş bir yelpazede katılımlarını sağlamayı hedeflemelidirler. Bu şekilde uygun maliyetli modeller sponsor yelpazesinin genişlemesine ve yasal katılımın artmasına yol açacaktır.

Olimpiyatlarda dijital ve sosyal pazarlama konusu olimpik prensiplerle ekonomik kaygıların karşılaştığı bir polemik de yaratmaktadır. Olimpiyatın temel ilkelerine göre spor faaliyetlerine katılmak her sporcunun insani hakkıdır, her birey herhangi bir ayrımcılığa maruz kalmaksızın olimpiyat ruhu içinde spor yapma imkanına sahip olmalıdır. Ancak günümüzde olimpiyat Jacque Rogge’un 2012 Londra Olimpiyatları'nda ifade ettiği gibi; 'olimpiyat komitesi olarak sponsorların korunması zaruridir, çünkü aksi durumda sponsorluk olmayacak, sponsorluk olmazsa da olimpiyat oyunları tarih olacaktır', ticari olarak inanılmaz boyutlara ulaşmıştır ve bunun sonucunda ekonomik kaygılar nedeniyle sponsorlukların zarar görmemesi için bazı prensipler çiğnenmektedir.

Kural 40’ın olimpiyat prensipleri doğrultusunda değerlendirilmesi ve bireysel sponsorların sporcu gelişimi üzerindeki etkilerini artıran etkilerinin göz ardı edilmemesi gerekmektedir. Bu tarz sponsorluklarda bazı istisnalar yaratılarak sporcunun desteklenmesinin teşvik edilmesi doğru 
olacaktır. Sosyal medya kanalıyla yapılan paylaşımlarda bireysel sponsorların paylaşımı belli oranda IOC tarafından da desteklenmelidir. Bu noktada en doğru yöntem tüm tarafların bir araya toplanarak uygulamada doğan aksaklıklar da değerlendirilerek ortak çözüm alternatiflerinin geliştirilmesidir. Tabi ki haksız rekabet ve yasal olmayan reklam ve ürün satışı engellenmelidir, ancak amacı sadece sporu ve sporcuyu desteklemek olan girişimler konusunda adil bir uygulama süreci sağlanmalıdır. 


\section{KAYNAKÇA}

Arcelea.com, https://arcalea.com/7-creative-ways-brands-used-olympics-digital-marketing, 23.08.2016.

Bartoletti, M. (2013). The importance of social media in their contribution to the marketing of sport events. İşletme Lisans Tezi. Modul Viyana Üniversitesi, Viyana.

Bayless A (1988). Ambush marketing is becoming a popular event at Olympic Games. The Wall Street Journal, February 8.

Butts, F.B. (2008). NCSS athletes and Facebook, The Sport Journal, 11(1), 23-30.

Catalyst/IMG Study (2014). http://www.slideshare.net/bwerner10/fan-engagement-study-img-consulting, Erişim Tarihi: 06.01.2017.

Chadwick, S. ve Burton, N. (2011). The evolving sophistication of ambush marketing: A typology of strategies. Thunderbird International Business Review, 53(6), 709-719.

Clavio, G. (2011). Social media and the college football audience. Journal of Issues in Intercollegiate Athletics, 4, 309-325.

Eagleman, A.N. (2013). Acceptance, motivations, and usage of social media as a marketing communications tool amongst employees of sport national governing bodies. Sport Management Review, 16, 488497.

Ellis, D., Gauthier, M.E. ve Séguin, B. (2011). Ambush marketing, the Olympic and Paralympic Marks Act and Canadian national sports organisations: Awareness, perceptions and impacts. Journal of Sponsorship, 4(3), 253-271.

Emig, I. (2016). Trademarked hashtags for Rio 206 Olympics. Blasting News, 03.08.2016.

Ganes, C. (2016). Michael Phelps was forced to cover the logo of his Beats headphones and he did a lackluster job with the tape. Business Insider, 07.08.2016.

Grady, J., Ballouli, K., Pressley, A. ve Moorman, A.M. (2013). Regulating the twitter Olympics: Analyzing efforts to regulate social media and ambush marketing at the London 2012 olympics. 2013 NASSM Conference, 28.5.-01.06.2013, Austin, Teksas, USA.

Grady, J. (2011). Olympic ambush marketing and new media. 19 ${ }^{\text {th }}$ Conference of EASM, 7-10 Eylül 2011, Madrid, İspanya.

IOC (2016). IOC Marketing: Media Guide. International Olympic Committee.

Iokimidis, M. (2010). Online marketing for professional sport clubs: Engaging fans on a new playing field. International Journal of Sports Marketing\&Sponsorship, 11(4), 271-282.

Kaplan A. ve Haenlin, M. (2010). Users of the World, unite! The challenges and opportunities of social media. Business Horizons, 53(1), 59-68.

Krashinsky, S. (2016). Brooks launches ad campaign protesting Olympics advertising rules. The Globe and Mail, 05.08.2016.

Mahan, J.E. (2011). Examining the predictors of consumer response to sport marketing via digital social media. International Journal of Sports Management and Marketing, 9(3/4), 254-267.

Meenaghan, T. (1994). Point of view: ambush marketing: immoral or imaginative practice? Journal of Advertising Research, 34(5), 77-88.

Nufer, G. (2016). Ambush marketing in sports: an attack on sponsorship or innovative marketing? Sport, Business and Management: An International Journal, Vol. 6 (4), 476-495.

Payne, M. (1998). Ambush marketing: The undeserved advantage. Psychology\&Marketing, Vol.15(4), 323331. 
Pickton, D., Broderick, A. (2004). Integrated Marketing Communications. Financial Times/Prentice Hall, $2^{\text {nd }}$ Edition.

Portela, M. (2016). Rio 2016 top 10 ambush marketing cases. Portekiz Olimpiyat Komitesi, Blog.

Waters, R.D., Burke, K.A., Jackson, Z.J. ve Buning, J.D. (2010). Using stewardship to cultivate fandom online: Comparing how National Football League teams use their websites and Facebook to engage their fans. International Journal of Sport Communication, 3, 163-177.

Welsh, J. (2002). Ambush marketing: what it is, what it isn't. Business and Marketing Strategy.

Wysocki, M. (2012). The role of social media in sports communication: An analysis of NBA Teams' strategy. Yüksek Lisans Tezi, American University, Washington. 